de Uzawa Hirofumi (1928); dos valores sociais e crescimento industrial de Murakami Yasusuke (1931); da sociedade formada por redes de informações de Imai Kenichi (1931); e, finalmente, da tecrologia e o pensamento econômico de Sawa Takamitsu (1942).

Antes de terminar esta resenha, que a quantidade e importância dos assuntos e autores relatados por si só justificam a leitura do livro por todos os estudiosos do Japão, especialmente os das âreas de Economia e Administração e os de Ciências Políticas e Sociologia, resta-nos sugerir à editora Routledge, que já publicou a história econômica da Austrália, da Suécia e do Canadá; a publicação da história econômica do Brasil. É obvio que a publicação de tal obra só pode ser realizada após sua produção e, assim sendo, resta-nos o seguinte questionamento: é a história econômica brasileira pouco interessante que não merece ser estudada ou são nossos cientistas sociais pouco interessados que não estāo preocupados com nossa história econômica? 1

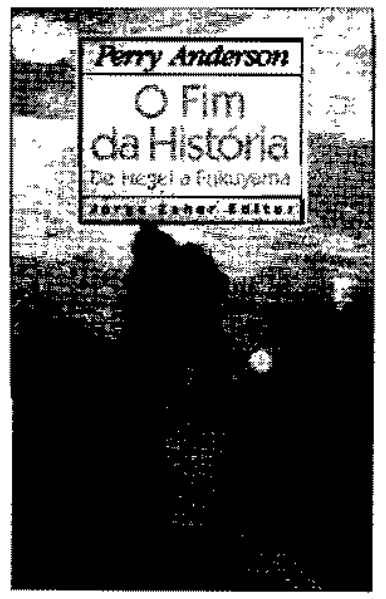

\section{O FIM DA HISTÓRIA: DE HEGEL A FUKUYAMA}

\section{de FRANCIS FUKUYAMA}

Rio de Janelro: Jorge Zahar Editor, $145 \mathrm{p}$.

Por Rosa Maria Vieira, Professora do Departamento de Fundamentos Sociais e Jurídicos da Administração da EAESP/FGV.

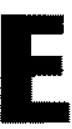
m 1989, Francis Fukuyama, funcionário do departamento de Estado norte-americano, publicou em Washington o ensaio The End of History?, transformado, três anos depois, no livro The End of History and Last Man que, logo a seguir, também fol editado no Brasil (O Fim da História e o Utitimo Homem, Rocco, 1992).
Valendo-se da interpretação de Hegel feita por Alexandre Kojève, Fukuyama defende a tese de que a humanidade chegou ao ponto final de sua evolução ideológica com o triunfo da democracia liberal sobre o fascismo e, mais contemporaneamente, sobre o comunismo. Vitorioso na Europa e, agora, em expansẫo pela Asia (Japäo, Coréia do Sul, Taiwan), este regime se estenderá, mais cedo ou mais tarde, a todos os povos civilizados, após a eliminação dos resíduos de passado histórico, localizados nas regiões subdesenvolvidas do Terceiro Mundo: nacionalismos e fundamentalismos impregnados de toxinas ideológicas e tensões étnico-políticas. Mais do que propriamente término dos conflitos ou mudanças circunstanciais, o fim da história representa, na realidade, o esgotamento de qualquer possibilidade alternativa para o capitalismo e suas manifestações democrático-liberais.

Obviamente a finitude da história humana tem custos: ideais heróicos dissipados na monotonia rotineira de comprar, consumir e votar, a arte e a filosofia definhadas e a imaginação política e moral substituídas pela razăo pragmática dos cálculos técnicos. Mas, em compensação, estão abertos, em definitivo, os horizontes ilimitados de desenvolvimento econômico.

Por se tratar de uma variante otimista e claramente política do discurso filosófico do fim da história, cuja tradição remonta ao final do século XVIII, a concepçăo de Fukuyama ganhou ampla difusão na mídia, numa estratégia de marketing, que o transformou num dos mais divulgados ideólogos neoconservadores da atualidade.

Mas a controvérsia pública gerada pela idéias de Fukuyama seguiu de perto a amplitude de sua divulgação: por motivos diversos, sociais-democratas, comunistas e mesmo alguns liberais e conservadores criticaram e rejeitaram suas teses. No âmbito da asquerda destacou-se, particularmente, Perry Anderson, antigo editor da prestigiada New Left Review, com o livro O Fim da História: de Hegel a Fukuyama, lançado no Brasil, em 1992, por Jorge Zahar Editor.

Para Anderson, a versão de Fukuyama do fim da história, apesar de ser produto atual da crise da URSS e do colapso do Leste Europeu, tem atrás de si uma "substancial e intrincada história" um background intelectual, cujo desvendamento esclarece as questões políticas embutidas nesta concepção. Por isto, nos três primeiros capitulos do livro, faz um levantamento das diferentes versoes do fim da história elaboradas a partir de Hegel, um dos principais avalistas filosóficos invocados por Fukuyama.

Tendo sempre como contraponto a vertente hegeliana do final do século XVIII, Perry Anderson analisa as idẻias de teóricos como Antoine-Augustin Cournot, o pioneiro da moderna teoria do preço: Alexandre Kojève, a segunda declarada inspiração de Fuku- 
yama, e, finalmente, um conjunto de pensadores contemporâneos como Henri de Man, Arnold Gehlen e Jürgen Habermas.

Rastreada a "intrincada história" existente atrás da versäo de Fukuyama, Anderson procura mostrar como os legados de Hegel e Kojève aí se combinaram de modo original. De Hegel vieram dois elementos: "o constitucionalismo da Rechtsphilosophie e o "otimismo de sua concepçâo do próprio fim como concretizaçano da liberdade na terra". De Kojeve, "o sentido de centralidade do hedonismo do moderno consumo, $e$ da caducidade da significaçäo tradicional do Estado Nacional ${ }^{\text {ts }}$. Em resumo, uma síntese onde se reuniram "a democracia liberal e a prosperidade capitalista num enfatico no terminal" (p. 81-82).

Segundo Anderson, a concepção de evolução humana de Fukuyama "exibe direcionalidade por causa do avantço cumulatioo do conhecimento técnico", impulsionado a partir do nascimento da ciência moderna. A razão cientifica obrigaria, com o tempo, todos os Estados a modernizarem-se, caso quisessem sobreviver às pressốes dos mais adiantados tecnologicamente e "a abrir horizontes ilimitados de desenvolvimento econônico para a satisfaçâo de necessidades materiais".

Impondo a racionalização do trabalho e da administraçâa, a ciência, de acordo com Fukuyama, elevou os padrões de vida a niveis antes inimagináveis, criando "tuma economia industrial madura", selecionando "o capitalismo como o unico sistema efictente - porque competitivo - para elevar a produtividade dentro de uma divisão global de irabalho" (p. 94-95).

Apesar de reconhecer que uma economia capitalista bem-sucedida não garante necessariamente a democracia política, Fukuyama, conforme observa Anderson, vê a revoluçăo liberal varrendo o globo e tornando irresistivel a força de seus princípios. A demonstraçấo empírica desta assertiva estaria no colapso de tantas ditaduras no mundo inteiro, de modo que a "democracia liberal subsiste como a única aspiração coerente que abarca diferentes regioes e culturas an todo o globo", não se podendo "imaginar para nós próprios um mundo essencialmente diferente do atual (...) democrático $e$ capitalista"(p.97).

Anderson dedica-se longamente ao desmonte desta argumentaçäo demonstrando seus limites, contradiçöes e implicaçöes ideologicas. Basta aqui, entretanto, seu questionamento quanto à projeçäo de um futuro taiwanês ou coreano para todo o mundo subdesenvolvido. Segundo ele, mesmo supondo-se que o crescimento de Taiwan (cuja renda per capita, entretanto, é apenas a metade da norte-americana) possa tomar-se corriqueiro para o Terceiro Mundo, não existe qualquer possibilidade real de reprodução dos modelos de consumo das áreas desenvolvidas. $O$ estilo de vida dos cidadãos do Primeiro Mundo depende necessariamente de sua restrição a uma minoria privilegiada.
"Se todas as pessoas da Terra possuíssem o mesmo número de getadeiras e automóveis que as da América do Norte e da Europa Ocidental, o planeta ficaria inabitável. Hoje, a ecologia global de capital, o privilégio de uns pou$c o s$, requer a miséria de muitos, para ser sustentável. Menos de um quarto da populaçấo do mundo detém atualmente $85 \%$ da renda mundial, $e$ a diferença entre as participaçôes das zonas azançadas e atrasadas ampliou-se ainda mais nos ultimos cinqüenta anos. (..) Nos anos 80, mais de 800 milhöes de pessoas - mais do que as populacôes da Comunidade Européa, Estados Unidos e Japäo somadas tornaram-se ainda mais excruciantemente pobres, e uma a cada três crianças passaza fome $e^{\prime \prime}$ (p. 110).

Por isso, talvez, nem mesmo Fukuyama conceba as relações entre "a zona pós-histórica de um afortunado capitalismo tiberal" e "a zona de infortúnio ainda enredada na historia de forma harmoniosa. Prevendo colisōes sugere, profilaticamente, a salvaguarda dos fornecimentos de petróleo, a filtragem da imigração dos miseráveis para os países ricos e o bloqueio da tecnologia avançada, notadamente, a bélica nuclear.

Para Perry Anderson, entretanto, não ê suficiente mostrar que a tese de Fukuyama atenua ou ignora os defeitos da ordem dominada pelo capitalismo liberal para reprová-la. É necessário indicar uma alternativa possivel, digna de crédito. A partir daqui seu livro sofre uma inflexão, pois nẫo se detém mais na avaliação das diferentes versōes do fìm da história ou na polêmica frontal com Fukuyama. Fazendo coro com os intelectuais de tradição marxista, que não identificam na crise do Leste a derrocada do socialismo, no capítulo final, analisa a situação contemporằnea da teoria socialista e as perspectivas de se enfrentar com êxito, a partir desta ótica, os problemas reais do mundo atual.

Munido das referências de alguns paradigmas da cultura de esquerda e considerando que "o estreitamento dos vinculos da ordem capitalista mundial está fadado, de qualquer modo, a forçar as tremendas pressóes de pobreza e exploraçáo no Sul a repercutir pela primeira vez no próprio Norte", criando-se "uma nova agenda internacional para a reconstrução nacional" "Perry Anderson acredita que o socialismo, capaz de equacionar as tensões e os conflitos, seria "redimido como legítimo programa para um mundo mais igual e mais habitável (p.42).

Pela importância e atualidade das questốes tratadas, pelo caráter e amplitude da abordagem, o livro de Perry Anderson é leitura obrigatória para quem pretende se aproximar da polêmica quanto ao caráter do devir histórico contemporâneo e do sentido da pretensão hegemônica do pensamento neoliberal, que apresenta a humanidade atual como negação das possibilidades de transformaçöes radicais do mundo capitalista. 0 